\title{
Digital Technologies in Enterprise Management
}

\author{
S.A. Chevereva ${ }^{l, *}$, E.S. Popova ${ }^{1}$, O.I. Grevtsev ${ }^{l}$ and T.B. Efimova ${ }^{1}$ \\ *Corresponding author: chevereva@yandex.ru
}

${ }^{1}$ Samara State University of Economics, Samara, Russia

\begin{abstract}
The aim of the study is to review methods and assess their impact on the organization. For this the operating companies was analyzed, the studied indicators of their effectiveness. This article discusses information technology and the degree of their influence on enterprise management, the ability of information technology to simplify the production process and motivate employees to achieve performance of the company in connection with the dynamic emergence of new ways of modernization. The result is a positive evaluation of the implementation of those or other methods identified situation for the most opportune moment of implementation that will help the current companies to make the right choice to optimize and choose the best option in the proposed conditions.
\end{abstract}

Keywords: information technology, gamification, the technique of the KPI, virtual ATC, Big Data, Manager.

\section{Introduction}

A Information technologies are widely used in all spheres of modern life, which marks the introduction in the organization of the production process, the activity of which is impossible without a corresponding management system. Constant updating of technology in the modern economic activity requires a careful approach to management, increasing efficiency which can be achieved by the efficient use of information technology systems [1]. Information technology is the process using the set of tools and methods for the collection, processing and transfer of data to obtain high-quality information about the state of any object, process or phenomenon.

The enterprise management system comprise1s the subject areas of organization, motivation and control of the production processes of the enterprise. Information technology is an integral part of this system, in order to implement software tools and methods of decision-making in different areas of the company such as production cycle, financial structure, management quality, which will greatly increase productivity and help to automate the management process.

Each company chooses the best option of automation of the production process. Importantly, the strategy provides and covers the management process as a whole and not its individual components. The choice of product is based on its price policy, assessment of the company's expenses and projected cash flow [2].

\section{Problem Statement}

A It is important to say that enterprise management is a high-tech process that requires special attention. This is done in order to improve labor efficiency. As a result, companies received the most productive optimization methods. They identified certain aspects of the realization, especially the implementation. This is the best optimization option.

\section{Research Questions}

So, questions began to appear: how can one improve efficiency? What are the types of optimization, due to which you can increase performance? Why gamification can be a way to motivate employees. While the KPI methodology also helps improve efficiency by selecting key indicators. Or the Big Data technology, which processes datasets, greatly, simplifying the work of company employees. What is the appropriate way to go?

\section{Purpose of the Study}

The purpose of the study was to compare optimization methods and their impact on the performance of the company. The main thing was to understand why the company chooses one or another method of optimization and, as a result, to determine the degree of influence of the digital economy in the management of a modern enterprise. 


\section{Research Methods}

For this, optimization methods were investigated, which companies choose one or another method, to which it eventually leads. So the Gamification method, the KPI method, Big Data, virtual ATC were considered and compared.

\section{Findings}

\subsection{Gamification}

Gamification is the process of using game thinking to engage the audience in solving problems; application of game methods in non-game processes. It cannot replace business processes, but contributes to their improvement. Indeed, in this case channels of motivation of employees and communication are involved [3].

The principle of motivation is key to this technique. Its essence lies in the selection of the most effective levers of influence for employees, being able to motivate them to the result. This can be a reward or the praise of people. But most companies use the gaming method of rewards.

In this situation, a gaming virtual platform is created in which employees earn bonuses and rewards. A uniform rating system is being formed, where everyone can see their own "growth zone". There is a competitive spirit and a desire to achieve a better result. The end result will be a gift in the form of electronic equipment, trips or an extra week of vacation. Here the company chooses the promotion for its colleagues. Everything is based on the principle of knowledge of the audience - the better you know what motivates it, the more effectively you will be able to influence it.

An example is the Enter retail chain, in which they invented the Olympiad game, which contains many disciplines. One of them is called Imago, where top managers evaluate the usefulness of the proposed ideas on a scale from 1 to 5 and score points, resulting in a list of distinguished employees. Quarterly 30 winners are selected from the total number of employees (approximately $1.2 \%$ of employees), who are awarded a trip to the most amazing places on earth.

As a method of using information technology in the management of an enterprise, gamification allows to solve a number of issues: it involves employees in the workflow without administrative efforts, helps to develop creativity and leads to improved feedback channels. An important feature is the ability of gamification to the development of corporate culture. X5 Retail Group aims to unite the team, and therefore introduce information technologies to build effective interpersonal relationships, so gamification leads to team building and building respect for the profession among employees.

\subsection{Virtual ATC}

Information technologies allow you to optimize the company's workflow and introduce advanced technologies that simplify the management process by providing employees with a single telephony, such as the Virtual ATC system, which is an effective service for companies that decide to replace a physical ATC or even the entire call center. It can be implemented in various ways, the most preferred for the organization. Among them are:

1. Provision of equipment: a software server is installed in the organization's premises and IP phones and all associated software applications are configured;

2. Provision of the domain;

3. Providing a platform: a virtual machine is allocated with the selected operating system and software;

4. Consolidation of regular users of the switch into a common tariff plan: this can be done using additional features such as voice menu, IVR, virtual conference room.

The program combines telephone numbers, which allows the head of the sales department or business owner to view all information about employee employment in real time via online monitoring. Another advantage will be the recording of telephone conversations of employees in order to further improve the quality of customer service. In this case, office and mobile telephony are combined, that is, if the client calls the employee to a mobile phone, it will be reflected in the company's line of calls without additional program settings. A single multichannel company number - 8,800 will be connected, and the call forwarding function will help to transfer the call to the employee regardless of his location, which allows the employee to be more mobile, able to quickly solve the problem from the consumer, which will improve the company's image and increase her rating.

Another advantage is the availability of black and white lists. They allow you to block unwanted subscribers or transfer them to a special manager who is prepared in advance for communication with a specific category of consumers. In this connection, a strategy of employee behavior with these clients is developed, a list of them is formed and when contacting the company, they are redirected to a fixed manager who is ready to deal with any issue.

Virtual ATC does not require the purchase of expensive equipment and sophisticated technical equipment. It will help to provide an office with telephony in a short time, as well as to organize an office anywhere in the world without a specific reference to the physical place.

Thus, virtual ATC helps to establish communication channels between colleagues, as well as between a client and an employee, which will lead to an increase in the client base, as well as allow for adjusting the management process; reduces costs and minimizes costs in the field of telephony equipment. 


\subsection{The technique of the KPI}

Information technologies are reflected in the KPI (key performance indicators) methodology, which is used by the company to analyze the performance of employees and improve their performance. It should be noted that this methodology is used in companies for employees whose work affects economic performance (for example, in an insurance company is introduced for insurance agents).

The method of calculating KPI consists in determining the weight for each indicator; in this case, it should total 1, then the data on the selected indicators will be analyzed for six months and a plan will be drawn up, after which KPI indicators will be calculated in Excel. Use the calculation formula:

KPI Index = KPI Weight * Actual / Purpose.

So you can clearly see the performance of the employee and the degree of compliance with the planned standards.

It should also be borne in mind that for each position are defined their tasks. As an example, consider the principle of compliance of key performance indicators with the level of organizational structure:

- level "CEO" (business owner) - Achievement of the first level goal (plan / fact);

- level "management" (heads of divisions) - Achievement of the goals of the second level + indicators of the organization of planned work (plan / fact);

- level "ordinary personnel" - Achievement of goals + execution of current tasks (plan / fact).

This is how an employee's motivational formula is formed, while the ratio between the fixed and variable parts of the employee's income will vary depending on the goals, the situation in the company, and market characteristics. This is the case when the value of the sum changes as a result of changing places, therefore this fact must be taken into account.

The KPI method is used by almost all companies engaged in direct sales. This tool motivates employees, combines their goals with the overall goals of the company, and also allows you to see gaps in the activities of employees and track at what stage they arose.

When selecting this system, it is very important to tell employees about its need, to be able to demonstrate in action, by launching it to start in a test mode, and then implement it on an ongoing basis and direct everyone to achieve a result.

Thus, the KPI methodology plays a large role in the management of an enterprise, introducing employee motivation channels, correcting lagging indicators and engaging staff to work with the subsequent achievement of enterprise goals.

\subsection{Big Data}

Information technology is constantly evolving and there are new ways to simplify the production process. So companies began to use Big Data technology to work with a huge amount of information. It helps to process data arrays, thereby optimizing the work of employees. Information is generated every second, so many companies began to invest in Big Data, and there are about $73 \%$ of them, which means that this system really works fine.

The essence of Big Data is that the information is distributed to the computing nodes, and the processing itself occurs without loss of performance. Moreover, the technology prevents fraud among customers. It is used for risk management, forecasting company results, calculating bonuses for employees. For example, Alfa Bank introduced Big Data back in 2013. With its help, they conduct an analysis of social networks and the behavior of users of the site, personalizing content [4].

We will visually see the advantages of Big Data:

1. It successfully processes information, stores and manages it (as compared with conventional databases);

2. It structures the data in one single and understandable form;

3. It allows you to create analytics and create more accurate forecasts based on the processed information.

As a result: you will be able to understand the business from the side of numbers, study competitors and learn about them new information, improve your product or service, increase the level of service, loyalty and customer focus, reduce unnecessary expenses [5].

Big data is widely used in HR in staff recruitment. For example, companies determine the appropriate methods of recruitment, getting rid of unnecessary stages of the interview. There was a case when the organization, after analyzing the data, realized that the most loyal employees were within a radius of $5 \mathrm{~km}$ of it, which led to its transfer to a more convenient area. The result was a decrease in turnover, moreover, without additional investments in motivation. Moreover, Big Data helps to solve clustering problems by distributing employees into categories with the subsequent calculation of benefits for each of them.

Thus, Big Data is a multifunctional tool in enterprise management. The scope of its application is versatile and includes various areas of the market. The performance of the company demonstrates its effectiveness; therefore, more and more organizations are beginning to use it [6].

\section{Conclusion}

From the above we can conclude that information technologies are widely used by companies to improve their performance. They change over time and are reflected in the art of enterprise management, allowing you to streamline working methods and lead to high performance indicators. 
The result was determined that all methods are effective and necessary for implementation, as they allow the company to become more presentable in the market and to compete with the high-tech counterparts. He added, however, that any digital transformation occurs with a change in the thinking organization, prioritization. For many companies, optimization is a fundamental change, but leads to tremendous results.

\section{References}

1. I.G. Akperov, Information technologies in management. Moscow: Center INFRA (2013). [in Rus.].

2. M.A. Vandelia, Information technologies in management: textbook for bachelors. Moscow: Yurayt (2013). [in Rus.].

3. M.S. Zemskova, Introduction of gamification in the personnel motivation process of generation Y. International Research Journal, 10(52), Part 1, 29-33. URL https://research-journal.org/wp-content/uploads/2011/10/10-152.pdf\#page=29 (2016). [in Rus.].

4. N. Marz, J.Warren, Big data. Principles and practice of building scalable data processing systems in real time. Publishing. Moscow: Williams (2017). [in Rus.].

5. V.A. Veretennikov, Big Data: Big data analytics today. Young Scientist, 32(166), 9-12. URL: https://moluch.ru/archive/166/45354/ (2017). [in Rus.].

6. I.A. Samoilova, Informatics: Big data processing technologies. Young scientist, 49(183), 26-27. URL: https://moluch.ru/archive/183/46957/(2017). [in Rus.]. 